\title{
Viabilitas dan Virulensi Fusarium oxysporum f. sp. cubense yang Dipreservasi dengan Liofilisasi
}

\author{
Viability and Virulence of Fusarium oxysporum $f$. sp. cubense after Preserved \\ under Liophylization
}

\author{
Iqna Khayatina Rusli ${ }^{1 *}$, Arif Wibowo ${ }^{2)}$, \& Christanti Sumardiyono ${ }^{2)}$ \\ 1) Balai Karantina Pertanian Tanjung Priok \\ Jln. Enggano No. 17, Tanjung Priok. Jakarta Utara 14310 \\ ${ }^{2}$ Departemen Hama Penyakit Tumbuhan, Fakultas Pertanian, Universitas Gadjah Mada \\ Jln. Flora No. 1, Bulaksumur, Sleman, Yogyakarta 55281 \\ *Penulis untuk korespondensi.E-mail:narusli13@gmail.com
}

Diterima 6 Juni 2017; diterima untuk diterbitkan 26 September 2017

\begin{abstract}
Wilt disease caused by Fusarium oxysporum $f$. sp. cubense (Foc) is still pose as constraint to banana production all over the world. The objective of this research was to examine the viability and virulence of Foc isolates which had been preserved with lyophilization for 18 years. The experiment used 19 isolates of Foc, which were Pekulo, Sukorejo, Kali Sepanjang, Kalibaru, Purwojoyo, Prembun, Mulyosari, Sidogede, Sidatan, Kemiri, Juwangen, A-17, A-11, PS-5, B4-3-1, Fo2.16.16., PS-10, A-2, and Irja. The results showed that 12 isolates could grow well on PDA medium, namely Pekulo, Sukorejo, Kali Sepanjang, Kalibaru, Purwojoyo, Prembun, Mulyosari, Sidatan, Juwangen, PS-5, B4-3-1, and Fo2.16.16. Meanwhile, seven isolates (Sidogede, Kemiri, A-17, A-11, PS-10, A-2, and Irja) could not grow or develop on PDA medium. The result of pathogenicity test showed that six tested Foc isolates had very high virulences, with disease severity index of about 2.14-2.71. Other three isolates revealed high virulences with disease severity index around 2.012.07. Meanwhile, another three less virulent isolates demonstrated disease severity index in the range of 1.39-1.67
\end{abstract}

Keywords: isolate, pathogenicity, PDA

\section{INTISARI}

Penyakit layu yang disebabkan oleh jamur Fusarium oxysporum f. sp. cubense (Foc) masih menjadi kendala dalam produksi pisang di seluruh dunia. Tujuan dari penelitian ini adalah untuk menguji viabilitas dan virulensi isolat $F o c$ yang telah dipreservasi dengan liofilisasi selama 18 tahun. Penelitian menggunakan 19 isolat Foc yaitu Pekulo, Sukorejo, Kali Sepanjang, Kalibaru, Purwojoyo, Prembun, Mulyosari, Sidogede, Sidatan, Kemiri, Juwangen, A-17, A-11, PS-5, B4-3-1, Fo2.16.16., PS-10, A-2, dan Irja. Hasil penelitian menunjukkan bahwa 12 isolat Foc mampu tumbuh dengan baik pada medium PDA yaitu Pekulo, Sukorejo, Kali Sepanjang, Kalibaru, Purwojoyo, Prembun, Mulyosari, Sidatan, Juwangen, PS-5, B4-3-1, dan Fo2.16.16. 7 isolat tidak mampu tumbuh pada medium PDA yaitu Sidogede, Kemiri, A-17, A-11, PS-10, A-2, dan Irja. Enam isolat Foc yang diuji memiliki virulensi sangat tinggi dengan indeks keparahan penyakit berkisar antara 2,14-2,71. Tiga isolat yang lain memiliki virulensi tinggi dengan indeks keparahan penyakit berkisar antara 2,01-2,07. Sedangkan 3 isolat lainnya memiliki virulensi yang lebih rendah dengan indeks keparahan penyakit berkisar antara 1,39-1,67.

Kata kunci: isolat, patogenisitas, PDA

\section{PENDAHULUAN}

Penyakit layu yang disebabkan oleh jamur Fusarium oxysporum f. sp. cubense (E.F. Smith) Snyder and Hansen (Foc) masih menjadi masalah serius yang dapat menghambat produksi pisang di seluruh dunia. Penyakit ini dikenal sebagai Panama disease yang merupakan kendala utama pada pisang di daerah tropis maupun subtropis (Su et al., 1986). Di Indonesia, infeksi berat terjadi pada pertanaman pisang baik yang dikembangkan secara komersil ataupun tradisional (Nasir et al., 2005).

Jamur Foc memiliki empat ras yang berbeda-beda virulensinya. Setiap ras memiliki strain dengan variasi genetik sangat spesifik serta menyerang berbagai pisang dengan genom yang berbeda (Bentley et al., 1998). Klasifikasi ras didasarkan pada patogenisitas- 
nya terhadap inang. Jamur ini juga mampu bertahan dalam tanah tanpa tanaman inang selama 40 tahun (Fourieet al., 2009). Ras 1 bersifat patogenik terhadap pisang bergenom AAA, AAAA, AAB, ras 2 menyerang pisang dengan genom $\mathrm{ABB}$ dan $\mathrm{AAAA}$, ras 3 menyerang Heliconia caribea, sedangkan ras 4 adalah ras paling ganas karena menyerang semua jenis pisang yang juga diserang oleh ras 1 dan 2 . Ras-ras dari patogen Foc tidak ditentukan secara genetik, tetapi merupakan kelompok isolat yang menyerang kultivar tanaman pisang yang berbeda di lapangan (Bentley et al., 1998).

Perubahan sifat yang sangat mudah terjadi pada suatu mikroorganisme mengharuskan adanya suatu metode penyimpanan agar jamur tetap dalam kondisi baik. Salah satu metode penyimpanan mikroorganisme jangka panjang adalah liofilisasi. yaitu metode penyimpanan yang paling populer dan banyak digunakan untuk penyimpanan jangka panjang mikroba. Metode ini cocok untuk menyimpan berbagai jenis mikroorganisme termasuk jamur (Clark, 2006 cit. Machmud, 2001).

Metode penyimpanan $L$-drying dalam ampul pada suhu $5^{\circ} \mathrm{C}$ telah terbukti dapat menyimpan koleksi mikroba seperti bakteri, aktinomisetes, khamir, dan jamur pada rentang waktu lima hingga 20 tahun dengan tingkat kematian yang rendah (Nagai et al., 2005). Koleksi dan penyimpanan mikroba diperlukan sebagai bahan pengkajian lebih lanjut, sumber biodiversitas, dan koleksi plasma nutfah mikroba (Riyadi et al., 2008).

Isolat Foc koleksi Laboratorium Teknologi Pengendalian Universitas Gadjah Mada yang telah diliofilisasi belum pernah dilakukan penumbuhan kembali. Penelitian ini bertujuan untuk menguji viabilitas dan virulensi beberapa isolat Fusarium oxysporum f. sp. cubense yang telah dipreservasi dengan liofilisasi.

\section{BAHAN DAN METODE}

\section{Penyiapan Isolat Foc}

Isolat Fusarium oxysporum f.sp. cubense yang digunakan ditampilkan pada Tabel 1.

\section{Pengamatan Kemampuan Tumbuh (Viabilitas)}

Isolat yang telah disimpan dengan cara liofilisasi ditumbuhkan pada medium Potato Dextrose Agar (PDA) dalam cawan petri dan diinkubasi selama tujuh hari. Pengamatan dilakukan dengan mengamati viabilitas isolat. Apabila isolat mampu tumbuh, kemudian diremajakan kembali pada medium PDA.

\section{Uji Virulensi pada Planlet Pisang Ambon Kuning}

Uji virulensi dilakukan dengan menggunakan isolat yang masih memiliki kemampuan tumbuh kemudian diinokulasi secara langsung pada planlet pisang ambon kuning berumur 9 bulan dalam botol kultur. Masing-masing perlakuan terdiri dari 4 ulangan.

Tabel 1. Daftar isolat Foc yang digunakan dalam penelitian

\begin{tabular}{ccccc}
\hline No & Kode Isolat & Kultivar & Asal Isolat & Tahun Liofilisasi \\
\hline 1. & Pekulo & Ambon & Banyuwangi, Jawa Timur & $24-06-1999$ \\
2. & Sukorejo & Ambon & Banyuwangi, Jawa Timur & $24-06-1999$ \\
3. & Kali Sepanjang & Ambon & Banyuwangi, Jawa Timur & $08-06-1999$ \\
4. & Kalibaru & Ambon & Banyuwangi, Jawa Timur & $24-06-1999$ \\
5. & Purwojoyo & Ambon & Banyuwangi, Jawa Timur & $08-06-1999$ \\
6. & Prembun & Ambon & Kebumen, Jawa Tengah & $10-07-1999$ \\
7. & Mulyosari & Ambon & Kebumen, Jawa Tengah & $24-06-1999$ \\
8. & Sidogede & Ambon & Kebumen, Jawa Tengah & $08-06-1999$ \\
9. & Sidatan & Ambon & Kulon Progo, DIY & $24-06-1999$ \\
10. & Kemiri & Ambon & Purworejo, Jawa Tengah & $24-06-1999$ \\
11. & Juwangen & Uter & Sleman, DIY & $08-06-1999$ \\
12. & A-17 & Ambon & Sleman, DIY & $24-05-1999$ \\
13. & A-11 & Ambon & Sleman, DIY & $24-05-1999$ \\
14. & PS-5 & Ambon & Sleman, DIY & $01-05-2002$ \\
15. & B4-3-1 & Ambon & Sleman, DIY & $24-05-1999$ \\
16. & Fo2.16.16 & Ambon & Sleman, DIY & $24-05-1999$ \\
17. & PS-10 & Ambon & Sleman, DIY & $01-05-2002$ \\
18. & A2 & Ambon & Sleman, DIY & $24-05-1999$ \\
19. & Irja & Ambon & & $24-06-1999$ \\
\hline
\end{tabular}


Isolat Foc yang berumur 7 hari pada medium PDA dipotong menggunakan bor gabus berdiameter 0,5 $\mathrm{cm}$. Inokulasi dilakukan dengan cara meletakkan empat potong isolat $F o c$ ke dalam botol yang berisi 4 planlet pisang ambon kuning. Kemudian diinkubasi pada growth chamber dengan suhu $22^{\circ} \mathrm{C}$.

\section{Pengamatan Gejala Layu/Kuning pada Daun}

Pengamatan dilakukan setiap hari mulai hari ketiga setelah inokulasi selama 4 minggu dengan mengamati dan menghitung jumlah daun yang menunjukkan gejala layu atau kuning, kemudian dilakukan analisis berdasarkan indeks gejala layu pada tanaman (LSI: Leaf Symptom Index) mengikuti metode Mak et al. (2004) yang dimodifikasi (Tabel 2).

Setelah indeks layu pada daun diperoleh kemudian dihitung DSI (Disease Severity Index) menggunakan rumus Mak et al. (2004) (Tabel 3):

$$
\frac{\sum(\text { skor } \times \text { jumlah daun pada skor tersebut })}{\sum \text { (jumlah semua daun yang diuji) }}
$$

Tabel 2. Indeks Layu pada Daun Leaf Symptom Index (LSI)

\begin{tabular}{cl}
\hline Skor & \multicolumn{1}{c}{ Keterangan } \\
\hline 0 & Tidak ada gejala layu/tanaman sehat \\
1 & $1-2$ daun kuning/layu \\
2 & 3 daun kuning/layu \\
3 & 5 daun kuning/layu \\
4 & $>5$ daun kuning/layu \\
\hline
\end{tabular}

sumber: Mak et al. (2004)

Tabel 3. Keterangan Disease Severity Index (DSI)

\begin{tabular}{cc}
\hline DSI & Keterangan \\
\hline 0 & Avirulen \\
$0,1-1$ & Moderat \\
$1,1-2$ & Virulen \\
$2,1-3$ & Sangat Virulen \\
\hline
\end{tabular}

sumber: Mak et al. (2004)

\section{HASIL DAN PEMBAHASAN}

\section{Viabilitas Isolat Fusarium oxysporum $f$.sp. cubense (Foc)}

Isolat Foc yang telah dipreservasi dalam bentuk liofilisasi selama 18 tahun berjumlah 19 isolat. Dua belas isolat masih mampu tumbuh dengan baik, sedangkan tujuh isolat yang lain tidak mampu tumbuh pada medium PDA (Tabel 4).

Berdasarkan Tabel 4, isolat yang mampu tumbuh dengan baik adalah Pekulo, Sukorejo, Kali Sepanjang, Kalibaru, Purwojoyo, Prembun, Mulyosari, Sidatan,
Juwangen, PS-5, B4-3-1-, dan Fo2.16.16. Isolat yang tidak mampu tumbuh adalah Sidogede, Kemiri, A-17, A-11, PS-10, A2, dan Irja. Waktu yang diperlukan jamur untuk tumbuh kembali pada medium PDA setelah diliofilisasi berkisar antara 2-5 hari. Isolat yang paling cepat tumbuh adalah Kali Sepanjang, sedangkan yang paling lama tumbuh adalah Purwojoyo dan isolat Fo2.16.16.

Hilangnya viabilitas pada beberapa isolat uji dapat disebabkan faktor teknis, misalnya pada saat penyimpanan atau pada proses pengampulan. Kematian isolat mikroba pada penyimpanan kering beku umumnya tidak disebabkan oleh faktor fisiologis seperti dehidrasi atau kekeringan sel, tetapi lebih disebabkan oleh derajat dan jumlah air residu yang terdehidrasi pada saat proses pengampulan (Mikata, 1999).

Menurut Ilyas (2007), perbedaan tingkat viabilitas antar isolat dapat disebabkan adanya perbedaan variasi dalam jenis dan umur isolat yang digunakan. Adanya variasi dalam jenis akan mempengaruhi perbedaan karakter fisiologis dan morfologis, termasuk di dalamnya kemampuan viabilitas dan tingkat toleransi terhadap adanya perubahan kondisi lingkungan. Secara umum, isolat jamur yang baik disimpan dalam ampul adalah yang telah dewasa dan telah matang sporanya. Secara morfologis dan fisiologis, spora yang telah matang sempurna memiliki ketahanan yang tinggi terhadap perubahan kondisi lingkungan sehingga secara alamiah dapat melakukan proses dormansi tanpa kehilangan kemampuan viabilitasnya. Sebaliknya, penggunaan kultur yang sporanya belum matang secara sempurna dapat menyebabkan spora lebih rentan terhadap perubahan lingkungan sehingga mudah kehilangan viabilitasnya.

\section{Virulensi Isolat Fusarium oxysporum $f$. sp. cubense (Foc)}

Pengukuran tingkat keparahan penyakit dapat dilakukan dengan membandingkan daun yang bergejala dengan seluruh daun pada tanaman yang diamati. Pada penelitian ini, dengan melihat keparahan penyakit pada daun planlet pisang ambon kuning terlihat adanya variasi tingkat virulensi. Pada Tabel 5 terlihat bahwa enam isolat Foc yang diuji menyebabkan infeksi sangat parah (sangat virulen) dengan indeks keparahan penyakit pada daun yang tinggi yaitu Sukorejo, Kali Sepanjang, Kalibaru, Prembun, PS-5, dan Fo2.16.16, dengan nilai DSI (Disease Severity Index) berkisar antara 2,10 hingga 2,71. Isolat Pekulo, 
Tabel 4. Viabilitas isolat Foc yang telah dipreservasi selama 18 tahun

\begin{tabular}{cccccc}
\hline No & Kode isolat & Tahun liofilisasi & Tanggal peremajaan & Daya tumbuh & $\begin{array}{c}\text { Waktu tumbuh } \\
\text { (Hari) }\end{array}$ \\
\hline 1. & & & & + & 3 \\
2. & Pekulo & $24-06-1999$ & $19-04-2016$ & + & 3 \\
3. & Kakorejo & $24-06-1999$ & $19-04-2016$ & + & 3 \\
4. & Kalibaru & $24-06-1999$ & $19-04-2016$ & + & 5 \\
5. & Purwojoyo & $08-06-1999$ & $19-04-2016$ & + & 3 \\
6. & Prembun & $10-07-1999$ & $19-07-2016$ & + & - \\
7. & Mulyosari & $24-06-1999$ & $19-07-2016$ & + & 3 \\
8. & Sidogede & $08-06-1999$ & $14-10-2016$ & - & - \\
9. & Sidatan & $24-06-1999$ & $19-04-2016$ & + & 3 \\
10. & Kemiri & $24-06-1999$ & $19-04-2016$ & - & - \\
11. & Juwangen & $08-06-1999$ & $14-10-2016$ & - & - \\
12. & A-17 & $24-05-1999$ & $14-10-2016$ & - & 3 \\
13. & A-11 & $24-05-1999$ & $14-10-2016$ & + & 3 \\
14. & PS-5 & $01-05-2002$ & $14-10-2016$ & + & 5 \\
15. & B4-3-1 & $24-05-1999$ & $14-10-2016$ & + & - \\
16. & Fo2.16.16 & $24-05-1999$ & $14-10-2016$ & & - \\
17. & PS-10 & $01-05-2002$ & $14-10-2016$ & - & - \\
18. & A2 & $24-05-1999$ & $14-10-2016$ & - & - \\
19. & Irja & $24-06-1999$ & $19-04-2016$ & & - \\
\hline
\end{tabular}

Tabel 5. Indeks keparahan penyakit pada daun planlet pisang ambon kuning (30 HSI)

\begin{tabular}{lcc}
\hline \multicolumn{1}{c}{ Isolat } & $\begin{array}{c}\text { Indeks keparahan } \\
\text { penyakit (DSI) }\end{array}$ & Keterangan DSI \\
\hline Pekulo & 2,07 & Virulen \\
Sukorejo & 2,71 & Sangat virulen \\
Kali Sepanjang & 2,52 & Sangat virulen \\
Kalibaru & 2,10 & Sangat virulen \\
Purwojoyo & 2,04 & Virulen \\
Prembun & 2,17 & Sangat virulen \\
Mulyosari & 2,01 & Virulen \\
Juwangen & 1,67 & Moderat \\
Sidatan & 1,39 & Moderat \\
PS-5 & 2,10 & Sangat virulen \\
B4-3-1 & 1,46 & Moderat \\
Fo2.16.16 & 2,14 & Sangat virulen \\
Kontrol & 0 & - \\
\hline
\end{tabular}

Purwojoyo, dan Mulyosari menyebabkan infeksi parah (virulen) dengan indeks keparahan penyakit lebih rendah berkisar antara 2,01 hingga 2,07. Isolat Juwangen, Sidatan, dan B4-3-1 menyebab-kan infeksi ringan (moderat) dengan indeks keparahan penyakit berkisar antara 1,39 hingga 1,67.

Keparahan penyakit berhubungan dengan virulensi patogen. Variasi virulensi selain disebabkan oleh variasi yang terjadi pada saat reproduksi aseksual, juga disebabkan oleh produksi toksin dari masingmasing isolat Foc yang diuji. Jamur Foc mampu memproduksi toksin asam fusarat (Groenewald, 2006). Asam fusarat dapat memengaruhi fungsi mitokondria, menghambat enzim katalase, serta mengganggu membran sel yang mengakibatkan kebocoran ion dan kematian sel (Ballio, 1981 cit. Jumjunidang et al., 2011).

Perlakuan kontrol pada uji virulensi ini dilakukan dengan planlet pisang ambon kuning tanpa inokulasi Foc. Pada tanaman kontrol tidak ditemukan adanya gejala menguning ataupun layu pada daun hingga akhir pengamatan (30 Hari Setelah Inokulasi). Jika dibandingkan dengan isolat yang diinokulasi $F o c$, terdapat perbedaan warna pada perakaran planlet (Gambar 1).

Berdasarkan Gambar 1, jika dibandingkan dengan planlet tanpa inokulasi Foc (kontrol), perakaran tanaman yang diinokulasi dengan $F o c$ terlihat berwarna hitam dan membusuk, sedangkan planlet kontrol terlihat kokoh serta pada ujung akar berwarna putih menandakan bahwa tanaman sehat dan tumbuh akar-akar yang baru. Hal ini menunjukkan bahwa adanya perubahan pada akar planlet yang terserang Foc berupa kerusakan akar yang menyebabkan tanaman menjadi bergejala. Foc menginfeksi pada akar, berkembang ke xylem, kemudian berlanjut ke bonggol dan batang semu yang mengakibatkan terganggunya transportasi air sehingga muncul gejala penguningan pada daun (Ploetz et al., 2000). 

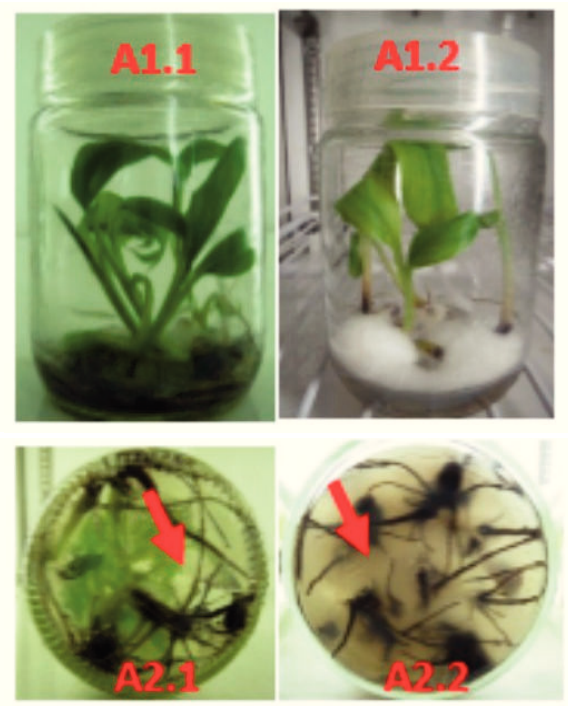
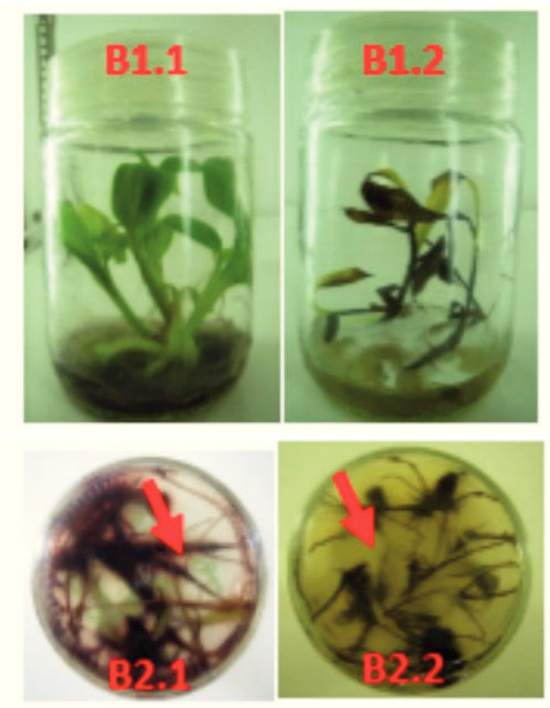

Gambar 1. Planlet pisang ambon kuning; planlet kontrol (A1.1), planlet yang telah diinokulasi dengan Foc isolat Kali Sepanjang pada 7 Hsi (A1.2), perakaran planlet kontrol (A2.1), perakaran planlet yang telah diinokulasi dengan isolat Kali Sepanjang pada 7 Hsi (A2.2), planlet kontrol (B1.1), planlet yang telah diinokulasi dengan isolat Kali Sepanjang pada $30 \mathrm{Hsi}$ (B1.2), perakaran planlet kontrol (B2.1), perakaran planlet yang telah diinokulasi dengan isolat Kali Sepanjang pada 30 Hsi (B2.2)

\section{KESIMPULAN}

Isolat Fusarium oxysporum f. sp. cubense (Foc) yang telah dipreservasi dengan liofilisasi memiliki viabilitas yang berbeda-beda dan mampu tumbuh pada $2-5$ hari setelah inkubasi. Isolat Foc yang diuji memiliki tingkat virulensi yang bervariasi. Isolat Sukorejo, Kali Sepanjang, Kalibaru, Prembun, PS-5, dan Fo2.16.16, menyebabkan infeksi sangat parah (sangat virulen) dengan nilai Disease Severity Index (DSI) berkisar antara 2,10 hingga 2,71.

\section{UCAPAN TERIMA KASIH}

Penulis mengucapkan terima kasih kepada Badan Karantina Pertanian yang telah membiayai sebagian dari penelitian ini. Naskah ini merupakan bagian dari tesis berjudul "Karakterisasi Isolat Fusarium oxysporum f. sp. cubense yang telah Dipreservasi dengan Liofilisasi”.

\section{DAFTAR PUSTAKA}

Bentley, S., K. G. Pegg, , N. Y. Moore, R. D. Davis,, \& I. W. Buddenhagen. 1998. Genetic Variation among Vegetative Compatibility Groups of Fusarium oxysporum f. sp. cubense Analyzed by DNA Fingerprinting. Phytopathology 88: 12831293.
Fourie, G., E. T. Steenkamp, T. R. Gordon, \& A. Viljoen. 2009. Evolutionary Relationships among the Fusarium oxysporum f. sp. cubense Vegetative Compatibility Groups. Applied and Environmental Microbiology 75: 4770-4781.

Groenewald, S. 2005. Biology, Pathogenecity, and Diversity of Fusarium oxysporum $f$. sp. cubense. Requirement for the Degree of Magister Science in the Faculty of Natural and Agricultural Science. University of Pretoria, Pretoria. 176 p.

Ilyas, M. 2007. Uji Viabilitas Koleksi Kapang LIPIMC dalam Ampul Penyimpanan Kering-beku $L$ drying setelah Satu Tahun Penyimpanan pada Suhu $5^{\circ} \mathrm{C}$. Biodiversitas 8: 20-22.

Jumjunidang, C. Hermanto, \& Riska. 2011. Virulensi Isolat Fusarium oxysporum f. sp. cubense VCG 01213/16 pada Pisang Barangan dari Varietas Pisang dan Lokasi yang Berbeda. Jurnal Hortikultura 21: 145-151.

Mahmud, M. 2001. Teknik Penyimpanan dan Pemeliharaan Mikroba. Buletin AgroBio 4: 24-32.

Mak, C., A.A. Mohamed, K.W. Liew, \& Y.W. Ho 2004. Early Screening Technique for Fusarium Wilt Resistance in Banana Micropropagated Plants. Banana Improvement. http://www.fao.org/ docrep/ 007/ae216e00.htm, diakses 18/2/16.

Mikata, K. 1999. Preservation of Yeast Culture by L-drying: Viability after 15 Years Storage at $5^{\circ} \mathrm{C}$. IFO Research Communications 19: 71-82. 
Nagai, T., T. Tomioka, K. Takeuchi, M. Iida, M. Kawada, \& T. Sato. 2005. Evaluation of Preservation Techniques of Microorganism Resources in the MAFF Genebank. Japan Agricultural Research Quarterly 39: 19-27.

Nasir, N., Jumjunidang. \& Riska. 2005. Deteksi dan Pemetaan Distribusi Fusarium oxysporum f. sp. cubense pada Daerah Potensial Pengembangan Agribisnis Pisang di Indonesia. Jurnal Hortikultura 5: 50-57.
Ploetz, R.C. \& K.G. Pegg. 2000. Fungal Disease of the Root, Corm, and Pseudostem, p. 143-172. In D.R. Jones (ed.), Disease of Banana, Abaca, and Enset. CABI Publishing, USA.

Riyadi, A.S., L. Soesanto, \& Kustantinah. 2008. Virulensi Fusarium oxysporum f. sp. zingiberi Isolat Boyolali dan Temanggung setelah Disimpan Enam Tahun dalam Tanah Steril. Jurnal Perlindungan Tanaman Indonesia 14: 80 - 85.

Su, H.J., S.C. Hwang, \& W.H. Ko. 1986. Fusarial Wilt of Cavendish Bananas in Taiwan. Plant Disease 70: 814-818. 